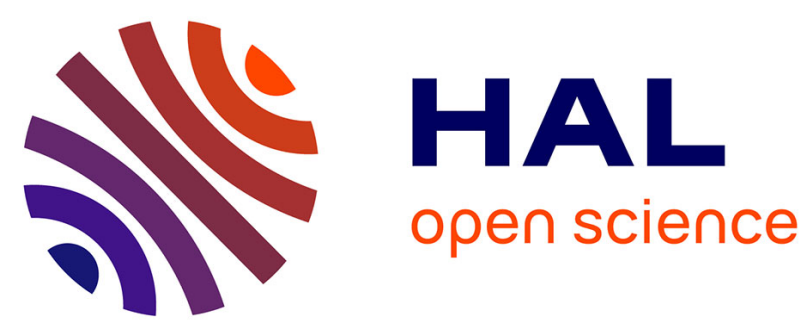

\title{
Real-Time 20 and 25 Gbit/s Pre-Equalized C-band Transmission With Electrical Duo-binary Detection
}

Justine Konopacki, Bertrand Le Guyader, Naveena Genay, Luiz Anet Neto, Fabienne Saliou, Sylvain Barthomeuf, Philippe Chanclou, Didier Erasme

\section{- To cite this version:}

Justine Konopacki, Bertrand Le Guyader, Naveena Genay, Luiz Anet Neto, Fabienne Saliou, et al.. Real-Time 20 and 25 Gbit/s Pre-Equalized C-band Transmission With Electrical Duo-binary Detection. ECOC, Sep 2017, Gothenburg, Sweden. hal-01572114

\section{HAL Id: hal-01572114 \\ https://hal.science/hal-01572114}

Submitted on 4 Aug 2017

HAL is a multi-disciplinary open access archive for the deposit and dissemination of scientific research documents, whether they are published or not. The documents may come from teaching and research institutions in France or abroad, or from public or private research centers.
L'archive ouverte pluridisciplinaire HAL, est destinée au dépôt et à la diffusion de documents scientifiques de niveau recherche, publiés ou non, émanant des établissements d'enseignement et de recherche français ou étrangers, des laboratoires publics ou privés. 


\title{
Real-Time 20 and 25 Gbit/s Pre-Equalized C-band Transmission With Electrical Duo-binary Detection
}

\author{
J. Konopacki ${ }^{(1-2)}$, B. Le Guyader ${ }^{(1)}$, N. Genay ${ }^{(1)}$, L. Anet Neto ${ }^{(1)}$, F. Saliou $^{(1)}$, S. Barthomeuf ${ }^{(1)}$, \\ P. Chanclou ${ }^{(1)}$, D. Erasme ${ }^{(2)}$ \\ (1) Orange Labs, 2 avenue Pierre Marzin 22307 LANNION, France, justine.konopacki@orange.com \\ (2) LTCI, Télécom ParisTech, Université Paris-Saclay, 75013 PARIS, France
}

\begin{abstract}
We experimentally demonstrate real-time C-band transmissions with up to $29 \mathrm{~dB}$ optical budget after $25 \mathrm{~km}$ propagation at $20 \mathrm{Gbit} / \mathrm{s}$ and $25 \mathrm{Gbit} / \mathrm{s}$. Our solution uses pre-equalization and electro-optical components dedicaded for $10 \mathrm{Gbit} / \mathrm{s}$ transmissions.
\end{abstract}

\section{Introduction}

Currently deployed G-PON ${ }^{1}$ (Gigabit capable Passive Optical Network) is based on the transmission of NRZ (Non Return to Zero) through direct intensity modulation of a laser source and direct detection at the receiver side. The NG-PON2 (Next Generation Passive Optical Network) standard has been recently defined by ITU-T ${ }^{1}$ (International Telecommunications Union) still based on NRZ modulation and combines both TWDM (Time and Wavelength Division Multiplexing). Presently, IEEE (Institute of Electrical and Electronics Engineers) and FSAN (full Service Access Network) / ITU-T are preparing new standards based on $25 \mathrm{Gbit} / \mathrm{s}$ modulated channels ${ }^{2}$. Whatever the technology chosen optical access equipment must remain low-cost.

In such a context, optical components previously designed for $10 \mathrm{Gbit} / \mathrm{s}$ operation exploiting spectrally efficient modulation formats such as EDB (Electrical Duo-Binary) or PAM (Pulse Amplitude Modulation) have been considered $^{3,4}$. In association with low chirp transmitters such as $\mathrm{EML}^{5}$ (Electro-absorption Modulated Laser) and with electrical equalization ${ }^{6}$, those formats help to mitigate $C D$ (Chromatic Dispersion) related system degradations.

In this paper, we demonstrate a real-time EDB reception scheme operating up to $25 \mathrm{Gbit} / \mathrm{s}$ in the C-band and using optical devices designed for $10 \mathrm{Gbit} / \mathrm{s}$ operation. We use a DML (Directly Modulated Laser) and an APD (Avalanche PhotoDiode) dedicated for $10 \mathrm{Gbit} / \mathrm{s}$ transmissions. Different emission formats are assessed: either a straightforward NRZ signal or an EDB signal combined (or not) with preequalization to improve performances at the Tx (transceiver) side. In both cases, EDB detection is used, combined (or not) with a EDB-to-NRZ converter.

\section{Pre-emphasis based duo-binary}

EDB modulation has recently caught the attention of the optical research community for optical access network applications thanks to its capability to increase the bit-rates per wavelength.

The EDB modulation reduces by a factor 2 the signal bandwidth with respect to an NRZ signal at the same data bit-rate. It artificially introduces some controlled intersymbol interference to the signal through a single-tap FIR (Finite Impulse Response) filter. The filter attenuates abrupt transitions such as "010" and "101" generating a third level in the eye-diagram. In order to prevent error propagation due to such operation, the original NRZ signal has to be pre-coded ${ }^{7}$. This is done by means of a simple XOR operation on symbols. When using some PRBS sequences for transmission experiments, it is not necesary to use a pre-coder. Tab. 1 represents a PRBS sequence pre-coded ("Prec" in Tab. 1) and not pre-coded. Then, the sequence is filtered into a EDB one ("EDB" in Tab. 1) thanks to the use of a FIR filter. Using two LA (Limiting Amplifier) on EDB and /EDB combined with a XOR gate as a decoder, makes it possible to recover the emitted sequence when the PRBS sequence is pre-coded. When the PRBS sequence is not pre-coded, the decoder output corresponds to a delayed and inverted version of the emitted sequence. The same phenomenon occurs for all PRBS sequences. Therefore, the precoder can be eliminated in the framework of an experimental evaluation if a PRBS stream is used.

\begin{tabular}{|c|c|c|}
\hline PRBS & \multicolumn{2}{|c|}{$\mathbf{1 1 0 0 1 0 1 1 1 0 0 1 0 1}$} \\
\hline Prec & 00010011110110 & $\mathrm{X}$ \\
\hline EDB & $--00-0+++00+0-$ & $+0-000++0-000+$ \\
\hline LA1 & 00000011100100 & 10000011000001 \\
\hline LA2 & 110010000000001 & 00100000010000 \\
\hline XOR & $\mathbf{1 1 0 0 1 0 1 1 1 0 0 1 0 1}$ & 10100011010001 \\
\hline
\end{tabular}

Tab. 1: Demonstration of a delay insertion in a duo-binary decoding sequence when using a PRBS $2^{3}$ length

Our first approach to generate a EDB signal is straightforward. We start from a PRBS 
a)

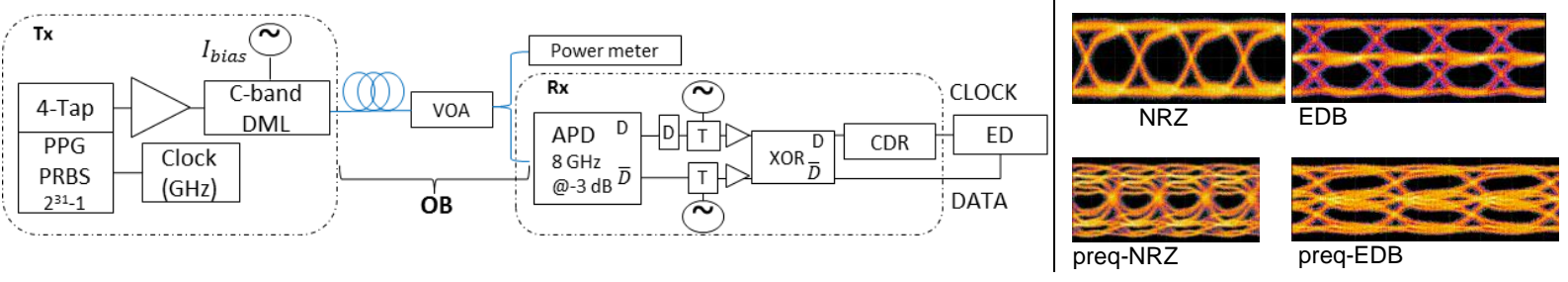

Fig. 1: a) NRZ, preq-NRZ, EDB and preq-EDB transmission with EDB receiver and EDB to NRZ converter experimental setup and b) Electrical modulated signal eye-diagrams at $20 \mathrm{Gbit} / \mathrm{s}$ associated (100 mV/div - $20 \mathrm{ps} / \mathrm{div})$

sequence and use two coefficients of a commercial 4-tap FFE (Feed Forward Equalizer) in order to create a conventional EDB signal by means of FIR filtering. The remaining two taps are used to improve transmission performance by means of pre-emphasis. A second approach consists in transmitting a standard NRZ signal and using the roll-off of the optical components and transmission channel to generate an EDB signal at the receiver side. In this case, the channel frequency response actually supersides the FIR filter of a conventional EDB transmitter. Furthermore, our 4-tap FFE is also used at Tx to improve performance, but with two extra coefficients compared to the first case. A third approach with a preq-NRZ (pre-equalized NRZ) signal at Tx side and a direct BER measurement at the receiver side is also evaluated in our experiments

\section{Transmission experimental setup}

The experimental setup depicted in Fig. 1.a provides some details on the optical emission and reception schemes.

A $2^{31}-1$ PRBS is generated by a PPG (Pulse Pattern Generator). Four configurations are generated thanks to a 4-tap FFE. First, a NRZ signal is generated at the $T x$. In a second approach, the NRZ signal is pre-equalized (preq-NRZ) by adjusting the three other taps. When using the first two taps with the same amplifier coefficients, the NRZ signal is converted into an EDB signal. The other taps are used to optimize the EDB signal (preq-EDB). Electrical eye-diagrams at $20 \mathrm{Gbit} / \mathrm{s}$ for the four configurations are depicted in Fig. 1.b. The resulting signal is amplified up to $4.5 \mathrm{Vpp}$ via an RF-amplifier for all cases and is used to directly modulate a $14 \mathrm{GHz}$ electrical bandwidth C-band DML. The latter emits $10.7 \mathrm{dBm}$ for a $110 \mathrm{~mA}$ bias current at $1550 \mathrm{~nm}$. Different optical fiber lengths (up to $40 \mathrm{~km}$ ) are used for the optical transmission and a VOA (Variable Optical Attenuator) allows assessing the maximum attainable OB (Optical Budget) for each scenario.
The receiver consists of an $8 \mathrm{GHz}$ electrical bandwidth APD equipped with an integrated trans-impedance amplifier. When the transmitted signal is a $20 \mathrm{Gbit} / \mathrm{s}$ or a $25 \mathrm{Gbit} / \mathrm{s}$ NRZ signals, it acts as a filter that transforms this NRZ signal into an EDB one. When a standard EDB signal is transmitted, the APD electrical bandwidth has a reduced influence on the signal. Finally an in-line EDB-to-NRZ converter scheme as explained before processes the received EDB signal. A CDR (Clock and Data Recovery) unit is used to synchronize the ED (Error Detector).

\section{Transmission performances in C-band at 20 and $25 \mathrm{Gbit} / \mathrm{s}$}

Fig. 2.a and Fig. 2.b represents C-band transmission performance at $20 \mathrm{Gbit} / \mathrm{s}$ and 25 Gbit/s respectively. Comparison between the various $B E R$ curves will be assessed through the determination of the OB penalty for a BER of $10^{-4}$.

The 20 Gbit/s (Fig. 2.a) BtB (Back-to-Back) evaluation is performed with both NRZ and EDB modulation formats. A $4 \mathrm{~dB}$ penalty can be observed for the EDB signal as compared to the $N R Z$. This can be explained by considering the same Vpp for both signal. The OB for the NRZ transmitter is $32.2 \mathrm{~dB}$ and is compliant with the legacy XGS-PON (10 Gigabit capable Symmetric Passive Optical Network) N1 class defined by ITU-T. As far as propagation is concerned, the pre-emphasis operation on the $N R Z$ and EDB signals are optimized so as to have an optimum performance at BER $10^{-4}$. The $\mathrm{NRZ}$ signal can be transmitted over $10 \mathrm{~km}$ with 29.6 dB OB without pre-equalization. Introducing pre-equalization, the optimized $\mathrm{NRZ}$ signal budget is increased by $1.2 \mathrm{~dB}$ to attain $30.8 \mathrm{~dB}$, becoming thus compliant with the $\mathrm{N} 1$ class. The same evaluation is made for the EDB and preqEDB signals exhibiting a $20 \mathrm{~dB} O B$ and a $27 \mathrm{~dB}$ $O B$ respectively. Introducing pre-equalization on EDB transmission to compensate CD increases significantly the performance. In fact, EDB allows a factor 2 reduction of the signal bandwidth with respect to an NRZ signal, 


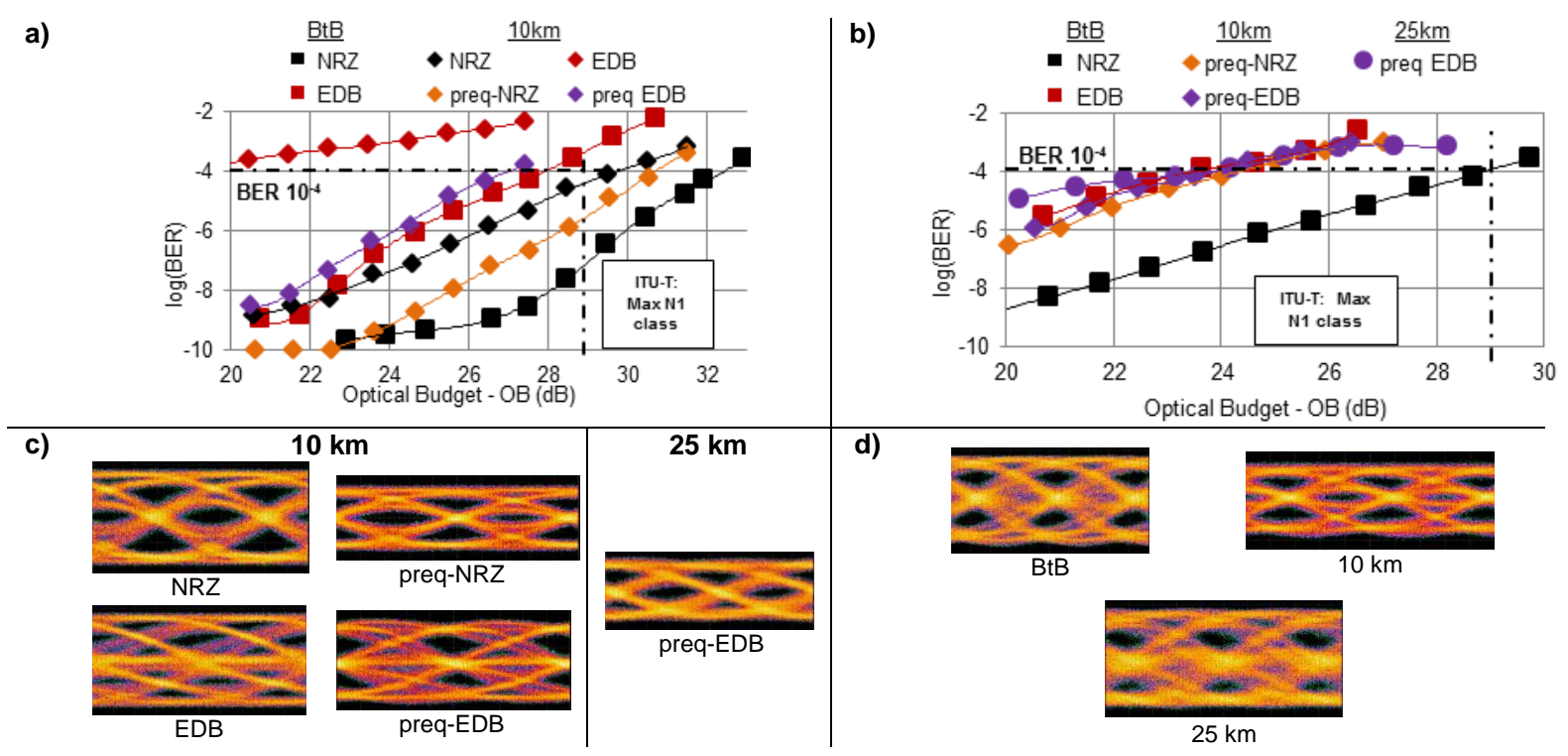

Fig. 2: a) $20 \mathrm{Gbit} / \mathrm{s}$ and b) $25 \mathrm{Gbit} / \mathrm{s}$ transmissions performances, c) $20 \mathrm{Gbit} / \mathrm{s} 10 \mathrm{~km}$ and $25 \mathrm{~km}$ eye diagrams after APD (100 mV/div - $10 \mathrm{ps} / \mathrm{div})$ and d) $25 \mathrm{Gbit} / \mathrm{s}$ eye-diagrams after APD (100 mV/div - $10 \mathrm{ps} / \mathrm{div})$

therefore egalisation is simplified for EDB. For a $10 \mathrm{~km}$ propagation, NRZ transmission outperforms EDB since CD and chirp effect are relatively low. BER curves for 25 and $40 \mathrm{~km}$ propagation with preq-EDB modulation (not displayed) exhibit $29.2 \mathrm{~dB}$ and $24.8 \mathrm{~dB}$ (for BER $10^{-3}$ ) respectively. For $25 \mathrm{~km}$ propagation and more, $C D$ is predominant. Therefore it is necessary to use a robust modulation format with a reduced spectrum.

Eye-diagrams at $20 \mathrm{Gbit} / \mathrm{s}$ measured after detection are displayed in Fig. 2.c. Preq-NRZ with $10 \mathrm{~km}$ propagation and preq-EDB with 25 $\mathrm{km}$ propagation eye diagrams make it possible to measure the BER directly after the APD. Results are depicted in Tab.2, and show increased performances by $+1.8 \mathrm{~dB}$ for $25 \mathrm{~km}$ propagation.

Fig. 2.b and Fig. 2.d present the transmission performance at $25 \mathrm{Gbit} / \mathrm{s}$ and eye-diagrams associated. BtB NRZ transmission reaches 29 $\mathrm{dB} O B$, whereas the EDB is only $23.5 \mathrm{~dB}$. In the case of $10 \mathrm{~km}$ propagation preq-NRZ modulation exhibits a $24.4 \mathrm{~dB}$ OB. Finally in the case of $25 \mathrm{~km}$ propagation, only preq-EDB modulation can be performed and exhibits a 24 $\mathrm{dB}$ OB. Performances are lower than with 20 Gbit/s data bit rate. Limiting the optical bandwidth at $\mathrm{Tx}$ is not sufficient to permit the

\begin{tabular}{|c|c|c|}
\hline Data rate & 20 Gbit/s & 25 Gbit/s \\
\hline BtB & $\begin{array}{c}32.4 \mathrm{~dB} \text { NRZ } \\
30 \mathrm{~dB} \text { w/o decoder }\end{array}$ & $29 \mathrm{~dB} \mathrm{NRZ}$ \\
\hline $\mathbf{1 0 ~} \mathbf{~ k m}$ & $\begin{array}{c}30.8 \mathrm{~dB} \text { preq-NRZ } \\
29 \mathrm{~dB} \text { w/o decoder }\end{array}$ & $24.4 \mathrm{~dB}$ preq-NRZ \\
\hline $\mathbf{2 5} \mathbf{~ k m}$ & $\begin{array}{c}29.2 \mathrm{~dB} \text { preq-EDB } \\
31 \mathrm{~dB} \text { w/o decoder }\end{array}$ & $24 \mathrm{~dB}$ preq-EDB \\
\hline $\mathbf{4 0} \mathbf{~ k m}$ & $\begin{array}{c}24.8 \mathrm{~dB} \text { preq-NRZ } \\
\text { (BER 10-3) }\end{array}$ & \\
\hline
\end{tabular}

Tab. 2: Optical budget at BER $10^{-4}$ at 20 and $25 \mathrm{Gbit} / \mathrm{s}$ with EDB to NRZ decoder signal to be more robust to CD.

\section{Conclusions and perspectives}

In this paper, real-time experimental transmissions at 20 and $25 \mathrm{Gbit} / \mathrm{s}$ in the C-band using electro-optical components dedicaded for $10 \mathrm{Gbit} / \mathrm{s}$ operation were evaluated. The setup is based on a modulable modulation using a 4-tap FFE. The receiver is based on an EDB detection using an $8 \mathrm{GHz}$ APD followed by a EDB-to-NRZ converter. We demonstrate 20 Gbit/s transmissions up to $25 \mathrm{~km}$ with more than $29 \mathrm{~dB}$ OB at BER $10^{-4}$, compliant with the maximum of the $\mathrm{N} 1$ class. At $25 \mathrm{Gbit} / \mathrm{s}$, our system reaches $24 \mathrm{~dB}$ OB at BER $10^{-4}$ with $25 \mathrm{~km}$ propagation, compliant with the $\mathrm{N} 1$ class. Performances are worse due to the limited electrical bandwidth of the photodiode used. At $25 \mathrm{Gbit} / \mathrm{s}$, the filtering function of the APD used is too abrupt and thus not adapted to generate the EDB signal. We advocate using a larger electrical bandwidth APD in order to improve performances in this case.

\section{References}

[1] D. Nesset, "PON Roadmap [Invited]," JOCN, VOL.9, NO.1 (2017)

[2] "IEEE P802.3ca 100G-EPON PHY Task Force," IEEE Std 802.3-2015 (2016)

[3] C. Sun et al., "Transmission of 28-Gb/s Duobinary and PAM-4 signal Using DML for Optical Access Network," IEEE Photonics Technology Letters (2016)

[4] V. Houtsma et al.,"A Study of Options for High-Speed TDM-PON Beyond 10G," JLT, VOL.35, NO.4, (2017)

[5] D. van Veen et al., "Symmetrical 25-Gb/s TDM-PON With 31.5-dB Optical Power Budget Using Only Off-theShelf 10-Gb/s Optical Components," JLT, VOL.34, NO.7, (2016)

[6] Dr. Pulidindi Venugopal et al., "10Gbps Optical Line Using Electronic Equalizer and its Cost Effectiveness," IJET, VOL.5, NO.4 (2013)

[7] T. Franck,et al., "Duobinary transmitter with Low Intersymbol Interference," IEEE PTL, VOL.10, NO.4 (1998) 